Politisches Denken · Jahrbuch 2002 
In Verbindung mit der Deutschen Gesellschaft zur Erforschung des Politischen Denkens

Redaktionsanschriften:

Prof. Dr. Karl Graf Ballestrem

Geschichts- und Gesellschaftswissenschaftliche Fakultät

Katholische Universität Eichstätt

Universitätsallee 1, 85071 Eichstätt

Prof. Dr. Volker Gerhardt, Institut für Philosophie, Humboldt Universität Berlin, Unter den Linden 6, 10099 Berlin

Prof. Dr. Henning Ottmann

Geschwister-Scholl-Institut für Politische Wissenschaft, Universität München, Oettingenstr. 67, 80539 München

\section{Wissenschaftlicher Beirat:}

Karl Dietrich Bracher (Bonn), Reinhard Brandt (Marburg), Maurice Cranston (London) ( $\dagger$ ), John Dunn (Cambridge), Iring Fetscher (Frankfurt), Klaus Hartmann (Tübingen) $(\dagger)$, Wilhem Hennis (Freiburg), Dieter Henrich (München), Otfried Höffe (Tübingen), Hasso Hofmann (Berlin), Nikolaus Lobkowicz (Eichstätt), Hermann Lübbe (Zürich),

Odo Marquard (Gießen), Kenneth Minogue (London), Michael Oakeshott (London) (†), J. G. A. Pocock (Hopkins University), Melvin Richter (New York), Quentin Skinner (Cambridge), Michael Stolleis (Frankfurt) 


\section{Politisches Denken Jahrbuch 2002}

Herausgegeben von

Karl Graf Ballestrem, Volker Gerhardt,

Henning Ottmann und Martyn P. Thompson

Verlag J. B. Metzler

Stuttgart - Weimar 
Die Deutsche Bibliothek - CIP-Einheitsaufnahme

\author{
Politisches Denken : Jahrbuch ...; \\ Jahrbuch der Deutschen Gesellschaft zur Erforschung des Politischen Denkens. \\ - Stuttgart :, Metzler. \\ Erscheint jährlich.- Aufnahme nach 1991 (1992) \\ ISSN 0942-2307 \\ 1991(1992) -
}

Dieses Werk einschließlich aller seiner Teile ist urheberrechtlich geschützt. Jede Verwertung außerhalb der engen Grenzen des Urheberrechtsgesetzes ist ohne Zustimmung des Verlages unzulässig und strafbar. Das gilt insbesondere für Vervielfältigungen, Übersetzungen, Mikroverfilmungen und die Einspeicherung und Verarbeitung in elektronischen Systemen.

$$
\begin{gathered}
\text { ISSN 0942-2307 } \\
\text { ISBN 978-3-476-01826-7 } \\
\text { ISBN 978-3-476-02766-5 (eBook) } \\
\text { DOI 10.1007/978-3-476-02766-5 }
\end{gathered}
$$

(C) 2002 Springer-Verlag GmbH Deutschland

Ursprünglich erschienen bei J. B. Metzlersche Verlagsbuchhandlung

und Carl Ernst Poeschel Verlag GmbH in Stuttgart 2002

www.metzlerverlag.de

info@metzlerverlag.de 


\title{
Inhalt
}

\author{
HUBERTUS BUCHSTEIN \\ Öffentliche Stimmabgabe in modernen Gesellschaften. \\ Begründungen einer Alternative im 19. Jahrhundert \\ 1 \\ BERND LADWIG \\ Gibt es ein Recht auf Einwanderung?
}

18

KARSTEN MALOWITZ

Moral, Kritik und Selbstbestimmung.

Zum Problem des ethischen Relativismus - Eine philosophische Skizze zur politischen Ethik

41

JAN ALTMANN

Republikanische Wendung des Nationsdiskurses.

Zur Rhetorik von Ernst Cassirers Rede:

Die Idee der republikanischen Verfassung

61

REINHARD MEHRING

Hölderlin oder Goethe?

Martin Heidegger und Thomas Mann als ideenpolitische Antipoden

79

ALFONS SÖLLNER

Franz L. Neumann's Place in the History of Political Thought - a Sketch 97

\section{KARSTEN FISCHER}

Die Tugend, das Interesse und der Weltlauf.

Hegel jenseits des Etatismus 
Inhalt

ANDREAS HERBERG-ROTHE

Die Umkehrungen Hegels im Marxismus -

Methodologie und politische Theorie

128

HENDRIK HANSEN

Karl Marx: Humanist oder Vordenker des GULag?

152

\section{Rezensionen}

Winfried Brugger

Liberalismus, Pluralismus, Kommunitarismus.

Studien zur Legitimation des Grundgesetzes

(Marianne Kneuer)

177

Tine Stein

Demokratie und Verfassung an den Grenzen des Wachstums.

Zur ökologischen Kritik und Reform des demokratischen Verfassungsstaates

(Steffen Kailitz)

183

Wilhelm Bleek

Geschichte der Politikwissenschaft in Deutschland

(Joachim Detjen)

188

Ernst H. Kantorowicz

Götter in Uniform. Studien zur Entwicklung des abendländischen Königtums

(Stephan Schlak)

194

Walter Laqueur

Faschismus. Gestern - heute - morgen

(Steffen Kailitz)

197 
Inhalt

Sebastian Haffner

Geschichte eines Deutschen. Die Erinnerungen 1914-1933

Peter Gay

Meine deutsche Frage. Jugend in Berlin 1933-1939

Marcel Reich-Ranicki

Mein Leben

(Reinhard Mehring)

200

$\mathrm{Zu}$ den Autorinnen und Autoren 